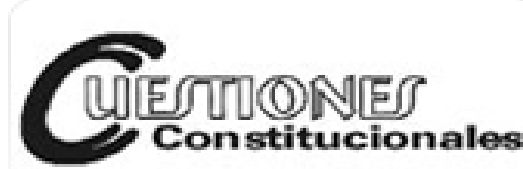

\section{Cuestiones Constitucionales}

ISSN: 1405-9193

rmdc@servidor.unam.mx

Universidad Nacional Autónoma de México

México

Sánchez Gil, Rubén A.

La jurisprudencia de inconstitucionalidad y su aplicación

Cuestiones Constitucionales, núm. 11, julio-diciembre, 2004, pp. 233-242

Universidad Nacional Autónoma de México

Distrito Federal, México

Disponible en: http://www.redalyc.org/articulo.oa?id=88501108

- Cómo citar el artículo

- Número completo

- Más información del artículo

- Página de la revista en redalyc.org

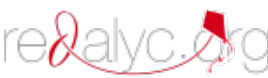

Sistema de Información Científica

Red de Revistas Científicas de América Latina, el Caribe, España y Portugal

Proyecto académico sin fines de lucro, desarrollado bajo la iniciativa de acceso abierto 


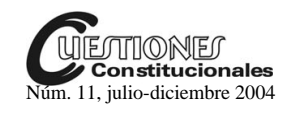

\title{
LA JURISPRUDENCIA DE INCONSTITUCIONALIDAD Y SU APLICACIÓN
}

\author{
Rubén A. SÁNCHEZ GIL*
}

\section{INTRODUCCIÓN}

La inconstitucionalidad de normas generales ha sido un problema largamente debatido en la doctrina jurídica mexicana. Aunque la absoluta mayoría de nuestros juristas —incluso los más conservadores- coincide en que resultan en la actualidad perniciosos los efectos de la fórmula Otero de nuestro juicio de amparo, aún no se ha llegado a un acuerdo sobre cuál es el sistema más conveniente para lograr la completa supremacía de nuestra Constitución, sin sujetarlo a los caprichos de las autoridades encargadas de controlar la constitucionalidad de leyes y otros actos.

El sistema que sugiere la tesis jurisprudencial P./J. 38/2002, ${ }^{1}$ emitida por el Pleno de la Suprema Corte de Justicia de la Nación, es un hito en nuestra historia jurisprudencial al permitir que las autoridades ordinarias omitan la aplicación de una norma general declarada inconstitucional por la jurisprudencia de nuestro máximo tribunal.

Este criterio nos conduce a nuevas reflexiones sobre la naturaleza de los criterios judiciales y su aplicación en casos concretos. La primera tesis que surge a raíz de la mencionada jurisprudencia de la Suprema Corte - de acuerdo con nuestro conocimiento- es la número VI.3o.A.151 A del Tercer Tribunal Colegiado en Materia Administrativa

\footnotetext{
* Profesor de la Facultad de Derecho de la UNAM.

1 "JURISPRUDENCIA SOBRE INCONSTITUCIONALIDAD DE UNA LEY. EL TRIBUNAL FEDERAL DE JUSTICIA FISCAL Y ADMINISTRATIVA SE ENCUENTRA OBLIGADO A APLICARLA, SIEMPRE QUE SEA PROCEDENTE, AL JUZGAR LA LEGALIDAD DE Un aCTO O RESOlUCión FUNDAdOS EN ESA LEY”, Semanario Judicial de la Federación y su Gaceta, novena época, t. XVI, agosto de 2002, p. 5.
} 
del Sexto Circuito; ${ }^{2}$ en ella, este órgano expresa que “el Tribunal Federal de Justicia Fiscal y Administrativa no debe señalar que la ley en que se apoyó el acto impugnado es inconstitucional, sino sólo que el referido acto es ilegal por fundarse en un precepto considerado inconstitucional por la Suprema Corte en jurisprudencia”, y éste es justamente el punto sobre el cual versará este comentario, intentando dar respuesta a las siguientes preguntas: ¿cuál es la naturaleza de la aplicación de la jurisprudencia?, ¿debe o no la autoridad ordinaria declarar la inconstitucionalidad de una norma general basada en la jurisprudencia que la afirma?

\section{LA JURISPRUDENCIA}

Cotidianamente quienes pretendemos cultivar el derecho, usamos el término "jurisprudencia" para referirnos indistintamente a los criterios emitidos por la judicatura. ${ }^{3}$ Es común encomendar al pasante la búsqueda de "jurisprudencia" para tal o cual asunto, en los cafés comentamos sobre la "jurisprudencia" que obliga al juez de distrito a estudiar los alegatos del quejoso cuando éste hace valer en ellos alguna causal de improcedencia del juicio de amparo $;^{4}$ y otros ejemplos a los que sería redundante aludir. Éste es el concepto de "jurisprudencia" en sentido lato: el conjunto de criterios utilizados por los tribunales para resolver la controversia que las partes de un proceso someten a su conocimiento.

Ahora bien, en un sentido técnico estricto se denomina "jurisprudencia" a aquellas interpretaciones y consideraciones jurídicas respecto de uno o varios puntos de derecho, que efectúa la autoridad jurisdiccional

2 “TRIBUNAL FEDERAL DE JUSTICIA FISCAL Y ADMINISTRATIVA. CARECE DE COMPETENCIA LEGAL PARA DECLARAR LA INCONSTITUCIONALIDAD DE LEYES, AL APLICAR JURISPRUDENCIA DE LA SUPREMA CORTE DE JUSTICIA DE LA NACIÓN, EN TORNO A ESE TEMA", Semanario Judicial de la Federación y su Gaceta, t. XVIII, agosto de 2003, p. 1857.

3 Es generalmente aceptada la dicotomía semántica del término “jurisprudencia”: a) Ciencia del derecho y b) Aquellos criterios judiciales que bajo ciertas condiciones son de aplicación obligatoria; aunque también puede incluirse la acepción "popular" que ahora anotamos, referida al conjunto general de decisiones judiciales. Cfr. Acosta Romero, Miguel y Pérez Fonseca, Alfonso, Derecho jurisprudencial mexicano, 2a. ed., México, Porrúa, 2000, pp. 71 y 72; y Carranco Zúñiga, Joel, Poder judicial, México, Porrúa, 2000, p. 376.

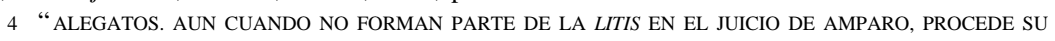
ESTUdio SI SE PROPONE UNA CAUSAL DE IMPROCEDENCIA", Segundo Tribunal Colegiado en Materia Civil del Segundo Circuito, Semanario Judicial de la Federación y su Gaceta, t. X, julio de 1999, tesis II.2o.C.44 K, p. 838. 
designada legalmente para tal efecto, de observancia imperativa para determinados sujetos — generalmente otros órganos jurisdiccionales- $;{ }^{5} \mathrm{y}$ se designa como "tesis aislada" o "precedente" a los criterios interpretativos acuñados por órganos jurisdiccionales, que no reúnen los requisitos legales para tener aplicación obligatoria. ${ }^{6}$

En nuestro país surge el sistema de jurisprudencia obligatoria por la influencia del common law estadounidense en los juristas liberales del siglo $\mathrm{XIX}^{7}$ aunque puede decirse que el sistema jurisprudencial mexicano es una creación original, formada a partir de la necesidad de desarrollar el juicio de amparo y debida principalmente a José María Iglesias, Ignacio Mariscal e Ignacio Luis Vallarta. Formalmente se establece, aunque rudimentariamente y circunscrito a la práctica del juicio de garantías, en los artículos 34 y 70 de la Ley de Amparo de 1882, que seguidamente trascribimos: ${ }^{8}$

Artículo 34. Las sentencias pronunciadas por los jueces, serán en todo caso fundadas en el texto constitucional de cuya aplicación se trate. Para su debida interpretación se atenderá al sentido que le hayan dado las ejecutorias de la Suprema Corte y las doctrinas de los autores [cursivas añadidas].

Artículo 70. La concesión o denegación del amparo contra texto expreso de la Constitución o contra su interpretación fijada por la Suprema Corte, por lo menos en cinco ejecutorias uniformes, se castigará con la pérdida de empleo, y con prisión de seis meses a tres años, si el juez ha obrado dolosamente; si obró por ignorancia o descuido, quedará suspenso de sus funciones un año [cursivas añadidas].

Actualmente nuestro sistema de jurisprudencia se establece a nivel federal en el octavo párrafo del artículo 94 constitucional y en los artículos 192 y 193 de la Ley de Amparo y 177 de la Ley Orgánica del Poder Judicial de la Federación.

5 Cfr. Burgoa Orihuela, Ignacio, El juicio de amparo, 33a. ed., México, Porrúa, 1997, p. 821.

6 En la práctica del derecho electoral, se denomina "tesis relevante" a aquellos criterios que no constituyen jurisprudencia, pero que aclaran el sentido dudoso de algún punto jurídico.

7 Cfr. Quiroz Acosta, Enrique, "El precedente en México y en los Estados Unidos de Norteamérica”, Lex. Difusión y Análisis, México, 3a. época, año IV, núm. 34, abril de 1998, p. 30.

8 Cfr. ibidem, p. 29; y Fix-Zamudio, Héctor, "Breve introducción al juicio de amparo mexicano", Ensayos sobre el derecho de amparo, 2a. ed., México, Porrúa, 1999, pp. 74 y 75. La Ley de Amparo de 1882 y los demás ordenamientos que han regulado nuestro juicio de amparo, pueden encontrarse en Álvarez Montero, José Lorenzo, 150 años de legislación de amparo 1847-1997, Xalapa, Instituto Mexicano del Amparo, 1997. 
La obligatoriedad de la jurisprudencia tiene las siguientes implicaciones:

a) Sólo puede constituir jurisprudencia stricto sensu, y por ende ser obligatorio, aquel criterio judicial que reúne determinadas características señaladas de forma expresa por la ley, al menos en nuestro sistema jurídico: instancia y procedimiento de origen, determinada reiteración, etcétera.

b) La aplicación de los criterios que constituyen jurisprudencia se realiza dogmática y taxativamente por los órganos vinculados a su observancia, independientemente de que compartan o no su sentido.

c) En virtud de que no son de aplicación obligatoria las tesis sin valor jurisprudencial, el juzgador que pretenda hacer uso de ellas debe hacer un análisis del criterio que contienen y los hechos de los cuales se originó, con el fin de corroborar que deriva de un correcto razonamiento de acuerdo con los principios y técnicas de la ciencia jurídica pues, de aplicar dicho criterio sin efectuar ese estudio, afectaría la garantía de legalidad establecida en los artículos 14 y 16 constitucionales -especialmente respecto a la debida motivación de su resolución-, pues no se aclararían las razones que tuvo para aplicar precisamente ese criterio y no uno diferente, dejando en indefensión al justiciable. ${ }^{9}$

La jurisprudencia tiene, en términos generales, las funciones de interpretar la ley o integrar las lagunas que ésta contenga, con la finalidad de lograr certeza jurídica a través de la unificación de criterios para la aplicación del derecho — de allí la necesidad de su obligatoriedad—. ${ }^{10}$ En el género de la jurisprudencia interpretativa hallamos la especie que denominamos "jurisprudencia de inconstitucionalidad", constituida por aquellos criterios que establecen las razones para sostener la irregularidad de una norma general respecto de la Constitución.

\footnotetext{
9 Recordemos que el artículo 16 constitucional dispone que debe motivarse la "causa legal" del acto de molestia ocasionado por la autoridad, lo que tiene por finalidad expresar al gobernado las razones que dieron origen a dicho acto, con el fin de que pueda conocer cabalmente por qué está siendo afectado. Sobre este tema puede consultarse la abundante bibliografía y jurisprudencia que detallan los alcances de dicha garantía.

10 Cfr. Acosta Romero y Pérez Fonseca, op. cit., nota 3, pp. 93-148.
} 


\section{LA APLICACIÓN DE LA JURISPRUDENCIA}

La obligatoriedad de la jurisprudencia stricto sensu - y sólo a ésta nos referiremos en lo sucesivo- es el elemento necesario para que logre su objetivo de unificar la interpretación y aplicación del derecho. Si los criterios que forman la jurisprudencia no resultaren de observancia imperativa para los órganos jurisdiccionales, éstos tendrían la posibilidad de emplear aquel que más les acomode, con grave detrimento de la seguridad jurídica que es el fin esencial del orden jurídico. ${ }^{11}$

Las autoridades jurisdiccionales que aplican en sus resoluciones los criterios jurisprudenciales, efectúan esta acción en virtud de una disposición expresa de la ley, que deben cumplir en obsequio del principio de legalidad establecido en los artículos 14 y 16 constitucionales -específicamente la garantía de fundamentación que este último contiene- ${ }^{12}$ pues, de no utilizar en sus decisiones la jurisprudencia, actuarían arbitrariamente al no tener fundamento para llevar a cabo dicha omisión.

Lo anterior nos hace considerar que la aplicación de la jurisprudencia es taxativa e inexorable para los juzgadores, ya que no se encuentran autorizados a omitirla a pesar de discrepar del criterio que contiene. Además, dicha aplicación se efectúa bajo la presunción juris et de jure de que el contenido de la jurisprudencia es verdadero y correcto, y constituye una recta interpretación y aplicación del derecho, de aquí que afirmemos que también es aplicada dogmáticamente por los tribunales obligados a ello; ${ }^{13}$ esta presunción se debe a la elevada autoridad del tribunal que la haya acuñado, otorgada en el entendido de que sus integrantes son juristas con sólidos conocimientos jurídicos, moralidad intachable y talento para la interpretación y aplicación del derecho.

La jurisprudencia entonces es una regla de aplicación jurídica de uso recomendable por la certeza sobre su corrección metodológica, impuesta por la presunción antes mencionada, en virtud de lo cual se impone su empleo a diversos tribunales con el fin de que utilicen en sus resoluciones dicho criterio y no otro que resulte "erróneo". En tales circunstancias,

11 Cfr. Recaséns Siches, Luis, Tratado general de filosofía del derecho, 14a. ed., México, Porrúa, 1999, pp. 220-226.

$12 C f r$. Burgoa Orihuela, Ignacio, Las garantías individuales, 32a. ed., México, Porrúa, 2000, pp. 602-604.

13 Cfr. Recaséns Siches, op. cit., nota 11, p. 5. 
los tribunales no tienen necesidad de analizar las cualidades jurídicas de la ratio decidendi de la jurisprudencia que aplican, sino que pueden —y deben - emplearla constatando únicamente la semejanza que exista entre los hechos que le dieron origen y los pertenecientes al caso concreto que actualmente deben resolver. ${ }^{14}$

Esto generalmente no resulta difícil de establecer, pues generalmente los juzgadores sólo utilizan los criterios jurisprudenciales para determinar la legalidad e ilegalidad de ciertos actos conforme a la competencia que tengan, o declarar la existencia de un derecho establecido en las leyes ordinarias. Por las razones que luego expondremos, el problema se suscita cuando la jurisprudencia que la autoridad ordinaria debe aplicar establece la inconstitucionalidad de una norma general, lo que intenta aclarar —al menos de modo incipiente— la tesis VI.3o.A.151 A del Tercer Tribunal Colegiado en Materia Administrativa del Sexto Circuito.

\section{LA TESIS DEL TERCER TRIBUnAl COLEGIAdO EN MATERIA ADMINISTRATIVA DEL SEXTO CIRCUITO}

Al resolver la revisión fiscal 80/2003, interpuesta por la Administradora Local Jurídica de Puebla Sur, el Tercer Tribunal Colegiado en Materia Administrativa del Sexto Circuito sentó el criterio sistematizado con el texto que a continuación se transcribe para facilitar su conocimiento: ${ }^{15}$

De conformidad con una recta paráfrasis de la jurisprudencia 38/2002, del Pleno de la Suprema Corte de Justicia de la Nación, legible en la Novena Época del Semanario Judicial de la Federación y su Gaceta, Tomo XVI, agosto de 2002, página 5, bajo el rubro: “JURISPRUDENCIA SOBRE INCONSTITUCIONALIDAD DE UNA LEY. EL TRIBUNAL FEDERAL DE JUSTICIA FISCAL Y ADMINISTRATIVA SE ENCUENTRA OBLIGADO A APLICARLA, SIEMPRE QUE SEA PROCEDENTE, AL JUZGAR LA LEGALIDAD DE UN ACTO O RESOLUCIÓN FUNDADOS EN ESA LEY", dicho tribunal carece de competencia para declarar la inconstitucionalidad de leyes, pues en el acto de aplicación de una jurisprudencia a un caso concreto, el juzgador sólo ejerce libertad de jurisdicción en la determinación relativa a si el referido caso se ciñe a los supuestos que lleven

14 Cfr. supra, nota 1.

15 Supra, nota 2. 
al empleo del criterio obligatorio, mas no en la postura que la jurisprudencia adopta, limitándose su actuación, una vez determinada la procedencia de la aplicación de la jurisprudencia, a nulificar el acto impugnado por el vicio de legalidad. Por tanto, la aplicación de una jurisprudencia sobre inconstitucionalidad a un asunto particular, por un tribunal constreñido a acatarla, no implica el pronunciamiento de éste sobre el tema jurídico en torno al cual verse la jurisprudencia, debido a que el órgano no estudia el problema de constitucionalidad, porque quien lo hizo fue la Suprema Corte al establecer la jurisprudencia; aquél sólo resuelve si el acto impugnado fue legal y podrá concluir en sentido favorable a los intereses del gobernado, si llegare a advertir que la norma en que se fundó el acto administrativo fue considerada violatoria de la Constitución por el órgano terminal competente para ello. Así las cosas, el Tribunal Federal de Justicia Fiscal y Administrativa, aun cuando está obligado por la jurisprudencia, no debe señalar que la ley en que se apoyó el acto impugnado es inconstitucional, sino sólo que el referido acto es ilegal por fundarse en un precepto considerado inconstitucional por la Suprema Corte en jurisprudencia, con independencia de que la comparta o no, debido a que no está facultado para declarar la inconstitucionalidad de una ley por más que exista jurisprudencia sobre el tema, en términos de lo establecido por el artículo 103, fracción I, de la Constitución Política de los Estados Unidos Mexicanos" (cursivas añadidas).

Desafortunadamente nos fue imposible conseguir oportunamente una copia de la ejecutoria de la cual deriva esta tesis, para establecer cuál fue el hecho concreto que produjo el criterio que contiene. Sin embargo, partamos de la intuición de que el Tribunal Federal de Justicia Fiscal y Administrativa señaló expresa e inequívocamente en la resolución impugnada en el expediente del que se origina dicha tesis, que alguna norma jurídica resulta inconstitucional de acuerdo con la jurisprudencia, y por ello declaró la nulidad de algún acto administrativo.

En primer lugar, nos parecen correctas algunas estimaciones del tribunal que emitió la tesis comentada, relacionadas con la aplicación en general de la jurisprudencia:

a) Que al determinar el uso de un criterio jurisprudencial, el juzgador sólo está facultado para establecer que el mismo es aplicable por coincidir la esencia de los hechos que lo originaron con los que forman el caso actual y concreto que debe resolver. 
b) Que el juzgador no puede decidir en relación con el sentido del criterio jurisprudencial, pues tiene el deber de aplicarlo independientemente de sus cualidades.

c) Como consecuencia de lo dicho en el inciso anterior, pero lo cual debe sentarse con toda claridad, tampoco está facultado el juez para analizar el tema sobre el cual versa la jurisprudencia en cuestión.

Sin embargo, no coincidimos con la afirmación del tribunal - que parte de lo considerado en la tesis P./J. 38/2002 - ${ }^{16}$ en el sentido de que la autoridad ordinaria debe limitarse a indicar la mera "ilegalidad" de un acto en sentido estricto apoyado en una ley declarada inconstitucional por la jurisprudencia, sin señalar en su resolución la inconstitucionalidad de dicha norma general.

\section{LA INCONSTITUCIONALIDAD DE UNA NORMA GENERAL Y SU DECLARACIÓN POR LA AUTORIDAD ORDINARIA}

Ciertamente, de acuerdo con la opinión del Pleno de la Suprema Corte de Justicia de la Nación, las autoridades ordinarias no tienen atribuciones para calificar la constitucionalidad de alguna norma general o acto, sino sólo el Poder Judicial de la Federación en uso de su jurisdicción constitucional, lo que se reitera en la tesis P./J. 38/2002 $2^{17}$ antes citada al señalar su texto que "los tribunales [ordinarios] carecen de competencia para resolver sobre la constitucionalidad de leyes". ${ }^{18}$

Sin embargo, hay que notar que un acto apoyado en una ley inconstitucional no es irregular en primera instancia por vicios de mera legalidad, sino por no ser conforme a las disposiciones de la ley fundamental, pues perfectamente dicho acto puede ser acorde con las normas legales y reglamentarias que le son aplicables y, no obstante, su invalidez debe ser establecida; si un determinado acto está apegado a lo que la ley ordinaria señala, su defecto no es entonces la "irregularidad legal" sino la "irregularidad constitucional", conceptos que no obstante ser análogos

16 Supra, nota 1.

17 Idem.

18 “CONTROL DIFUSO DE LA CONSTITUCIONALIDAD DE NORMAS GENERALES. NO LO AUTORIZA EL ARTículo 133 De La CONSTITUCiÓN”, Pleno, Apéndice al Semanario Judicial de la Federación 1917-2000, t. I, materia constitucional, tesis 159, p. 196; “CONTROL JUDICIAL DE LA CONSTITUCIÓN. ES ATRIBUCIÓN EXClusiva del PODER JUdiCial de LA Federación”, Pleno, Apéndice al Semanario Judicial de la Federación 1917-2000, t. I, materia constitucional, tesis 160, p. 197. 
difieren en su esencia. ${ }^{19}$ Ningún tribunal ordinario podría, empleando los términos en su estricto alcance científico, declarar la nulidad de un acto basado en una ley inconstitucional, apoyándose en un estudio de mera legalidad ni establecer su "ilegalidad" con base en la inconstitucionalidad de la que adolece, en caso de que dicho acto sea conforme con las disposiciones de la legislación secundaria. ${ }^{20}$

Es indispensable en una sentencia que declare la nulidad de un acto por vicios de inconstitucionalidad de la ley en que se funda, establecer tal condición con toda evidencia; de otra forma no se explicaría la privación de efectos jurídicos decidida sobre ese acto, si éste carece de vicios de mera legalidad. Ello no implicaría que la autoridad ordinaria se arrogue facultades ajenas ya que no analizaría cuestiones constitucionales, pues limitaría su actuación a utilizar la conclusión a la que arribó el tribunal que emitió la jurisprudencia de inconstitucionalidad, luego del estudio contenido en las ejecutorias relativas, al cumplir su deber de aplicarla dogmáticamente. En estos casos, hay que distinguir claramente quién es el que, con la competencia para ello, resuelve la inconstitucionalidad que afecta a una norma general; no es el tribunal ordinario que aplica la jurisprudencia, sino el tribunal que emitió ésta, quien realiza esa acción; aquél sólo se extiende, sin entrar al estudio del tema ni decidir la irregularidad constitucional de la norma con efectos vinculantes, al aplicar el criterio establecido en la tesis que debe usar al resolver, de acuerdo con su obligación constitucional y legal, realizando una mera homologación de la inconstitucionalidad ya analizada y afirmada por otra instancia jurisdiccional, que sí tiene autorización para ello; así también se da cumplimiento a lo dispuesto en la última parte del artículo 133 constitucional sobre el deber judicial de otorgar supremacía a la Constitución. ${ }^{21}$

19 Cfr. Kelsen, Hans, La garantía jurisdiccional de la constitución (la justicia constitucional), trad. de Rolando Tamayo y Salmorán, México, UNAM, Instituto de Investigaciones Jurídicas, serie Ensayos Jurídicos, núm. 5, 2001, p. 14.

20 Aunque es preciso aclarar que un defecto de mera legalidad también implica una violación al artículo 16 constitucional, pero la específica contravención a esta disposición únicamente podría resolverse por un juez constitucional según el criterio de la Suprema Corte de Justicia de la Nación.

21 El llamado "control difuso" de la constitucionalidad es un tópico bastante extenso y polémico como para que lo abordemos en esta ocasión. No obstante, cabe decir que en la tesis P./J. 38/2002 — citada en la nota 1 que antecede_, la Suprema Corte de Justicia de la Nación admite que los tribunales ordinarios cumplen el principio de supremacía constitucional establecido en el artículo 133 de nuestra ley fundamental, al declarar la nulidad de un acto fundado en una norma general declarada inconstitucional por la jurisprudencia. 
Lo anterior también encuentra apoyo en la opinión que expresa José María Lozano respecto de la declaración de inconstitucionalidad implicada en el amparo otorgado contra una norma general y los efectos relativos que la correspondiente sentencia debe tener: ${ }^{22}$

Hay que calificar como anti-constitucional la ley, calificaci[ó]n inevitable que el artículo constitucional (el 102) no impide en manera alguna. Lo que la Constitución prohíbe... es que en la parte resolutiva de la sentencia se declare que la ley [o] acto de que se juzga es anti-constitucional: el fallo debe limitarse a declarar que la justicia de la Uni[ó]n ampara y protege al quejoso contra una ley [o] acto reclamado" (cursivas añadidas).

Lo "prohibido" en el tema que nos ocupa no es señalar en la sentencia la inconstitucionalidad de la norma general, sino que la propia autoridad ordinaria decida en dicha resolución esa calidad, expresándolo así en los puntos resolutivos de su sentencia que son los que en realidad afectan la situación jurídica de las partes. ${ }^{23}$

Para finalizar, consideramos que la aplicación de la jurisprudencia de inconstitucionalidad no conlleva otorgar efectos generales a lo resuelto en las ejecutorias de la cual deriva. Como asentamos arriba, ${ }^{24}$ la jurisprudencia es un criterio abstracto para la aplicación del derecho, no una norma jurídica vinculante en forma directa para las partes de un proceso, las que en todo caso serían afectadas por la aplicación del criterio relativo que haga el juzgador en su resolución; dicho con otras palabras: el sentido de una específica jurisprudencia no modifica la esfera jurídica de las partes, la cual se afecta en realidad por la decisión del órgano jurisdiccional que — debido a su obligación legal- compartió y aplicó el criterio que constituye la tesis en cuestión.

22 Citado en Vallarta, Ignacio Luis, El juicio de amparo y el writ of habeas corpus, edición facsimilar, México, Francisco Díaz de León, 1881, p. 321.

23 Cfr. Dorantes Tamayo, Luis, Elementos de teoría general del proceso, 4a. ed., México, Porrúa, p. 341.

24 Supra, apartado II. 